\title{
Turismo rural pedagógico como prática educativa que favorece a aprendizagem: a impressão de um grupo de professoras
}

\section{Educational rural tourism as a pedagogical practice that promotes learning: the impression of teachers group}

\author{
Angela Luciane Klein (KLEIN, A. L.) ${ }^{*}$ e \\ Marcelino de Souza (SOUZA, M. de) ${ }^{* *}$
}

RESUMO - Os desafios que o sistema educacional apresenta ao longo destes últimos anos demandam práticas educativas inovadoras. Neste sentido, o presente artigo tem como propósito discutir a respeito da impressão de um grupo de professoras sobre o turismo rural pedagógico enquanto prática educativa que favorece a aprendizagem. Trata-se, pois, de um recorte da pesquisa científica realizada no ano de 2011, em nível de mestrado, cujas análises contemplaram duas experiências de turismo rural pedagógico: o projeto 'Viva Ciranda', em Joinville, SC e o Roteiro 'Caminhos Rurais' de Porto Alegre, RS. Metodologicamente, utilizou-se a pesquisa bibliográfica, a observação sistemática e entrevistas semiestruturadas, realizadas com 22 professoras, responsáveis pelas turmas de alunos que visitaram as propriedades rurais pedagógicas nos meses de agosto a novembro de 2011. Deste grupo, 14 atuavam em escolas municipais de Joinville e 8 em escolas particulares de Porto Alegre. Os resultados evidenciaram uma impressão favorável por parte das professoras. Para essas profissionais, as atividades desenvolvidas no âmbito das propriedades rurais, além de favorecer o aprendizado dos alunos em relação aos conteúdos específicos desenvolvidos em sala de aula, também possibilitaram a compreensão e valorização do trabalho do agricultor e das suas atividades produtivas. Conclui-se, desse modo, que a prática do turismo rural pedagógico emergiu como uma atividade que permite aos alunos experiências enriquecedoras e aos professores, uma maneira de ensinar os conteúdos trabalhados em sala de aula, relacionando teoria e prática, confirmada pelas impressões analisadas.

Palavras-chave: Educação; Práticas educativas; Turismo rural pedagógico.

ABSTRACT - The challenges that the educational system has shown over the last few years require innovative educational practices. In this sense, the current paper aims to discuss about the teachers' perceptions on educational rural tourism as a pedagogical

\footnotetext{
Formação: Graduação em Pedagogia e Especialização em Educação Ambiental pela Universidade Federal de Santa Maria (UFSM). Mestrado em Desenvolvimento Rural pela Universidade Federal do Rio Grande do Sul (UFRGS). Atividade profissional: Professora de Apoio Pedagógico do Ensino Fundamental. Prefeitura Municipal de Florianópolis. Endereço físico para correspondência: Rua João Gualberto Soares, n. 17.765, Barra da Lagoa. CEP 88061-500 - Florianópolis - Santa Catarina (Brasil). Email: angelaklain@yahoo.com.br

** Formação: Graduação em Agronomia pela Universidade Estadual de Londrina (UEL), Mestrado em Extensão Rural pela Universidade Federal de Santa Maria (UFSM) e Doutorado em Engenharia Agrícola pela Universidade Estadual de Campinas (UNICAMP). Atividade profissional: Professor Associado da Faculdade de Ciências Econômicas e do Programa de Pós Graduação em Desenvolvimento Rural da Universidade Federal do Rio Grande do Sul (UFRGS). Endereço físico para correspondência: Rua Vieira de Castro, 259/402, CEP 90040-320 - Porto Alegre - Rio Grande do Sul (Brasil). E-mail: marcelino.souza@uol.com.br
} 
practice that promotes students' learning. It is, therefore, a part of scientific research conducted in 2011, at a master degree level, which had analysis that were contemplated in two experiences of educational rural tourism: 'Viva Ciranda' project conducted in Joinville-SC and 'Caminhos Rurais' itinerary in Porto Alegre-RS. The methodology used the bibliographical research, systematic observation and semi-structured interviews accomplished with 22 teachers, responsible for groups of students who visited the educational farms from August to November 2011. From this group, 14 teachers were working in municipal schools from Joinville and 8 teachers were working in private schools from Porto Alegre. The results showed a favorable impression from the teachers. For these professionals, the activities developed in the context of rural properties, as well as promote student learning in relation to specific content developed in the classroom, also provided an understanding and appreciation of the farmer's labor and its productive activities. Therefore, it is concluded, that the practice of educational rural tourism has emerged as an activity that allows students enriching experiences and teachers, it is a way to teach the contents taught in the classroom, linking theory and practice, confirmed the impressions analyzed.

Key words: Education; Pedagogical practices; Educational rural tourism. 


\section{INTRODUÇÃO}

Vive-se um período de intensas transformações em que são exigidas novas habilidades e maior capacidade de abstração e atenção. Tais exigências requerem, por conseguinte, a necessidade de uma formação geral, envolvendo, dentre outros aspectos, o desenvolvimento de competências comunicativas e de capacidades criativas para analisar, pensar e agir com horizontes de maior amplitude (LIBÂNEO, 2004).

Diante dessa conjuntura, novos desafios emergem no campo da educação formal. De um lado, se observa uma geração de crianças e adolescentes que dominam com enorme rapidez e facilidade jogos eletrônicos, aparelhos celulares e internet, utilizando as tecnologias digitais na sua rotina diária, desde muito cedo. De outro lado, esta geração tem poucas oportunidades de experiências significativas, em contato com os animais, as plantas e com a terra. Assim, um dos desafios da escola está na incorporação de uma nova concepção de educação, com novas metodologias, que considerem não apenas a teoria, o ato de ler, mas, sobretudo, a experiência, o sentir, o experimentar (MAGALHÃES, 2004).

É nesse contexto que emerge o turismo rural pedagógico, uma atividade que do ponto de vista da educação tem se configurado como uma ferramenta de ensino importante. Um tipo de ação pedagógica que vai muito além da sala de aula, desenvolvida no âmbito das propriedades rurais em que os agentes educativos não são propriamente os professores das escolas, mas sim os agricultores e/ou proprietários rurais e cujos conteúdos são enriquecidos pelos saberes e fazeres, pelas suas práticas cotidianas, pelos costumes e tradições desses últimos.

Trata-se de uma proposta que contempla diferentes aspectos que vão desde o conhecimento de formas de produção e de processamento até a identificação de ações que podem favorecer a preservação ambiental. Ao mesmo tempo, também, "propicia o encontro de pessoas do meio urbano com a natureza, com as atividades agrícolas e, é claro, com outras pessoas, e por si só já se constitui em um ato pedagógico" (TEIXEIRA; WANDSCHEER; SOUZA, 2005, p. 137).

Para D'Agostino (2008), a prática desse tipo de atividade no âmbito das propriedades rurais pode representar uma ferramenta bastante útil, na medida em que favorecem a introdução das novas gerações no mundo rural, por meio da experiência 
direta, constituindo-se, desse modo, numa possibilidade de aprendizagem teórica e prática, a partir de uma interação estimulante. Também, Klein, Troian e Souza (2011, p. 119) ressaltam as questões ambientais associadas a esta atividade. Para os autores, o turismo rural pedagógico constitui "uma alternativa de desenvolvimento que incentiva o cuidado e a preservação dos recursos naturais e contribui para a ampliação do universo de conhecimento de crianças e adolescentes".

Partindo desses pressupostos, o presente artigo visa discutir a respeito da impressão de uma amostra de professoras sobre o turismo rural pedagógico enquanto prática educativa que favorece a aprendizagem dos alunos. A referida análise compreende um recorte da pesquisa científica intitulada 'Turismo rural pedagógico e a função educativa das propriedades rurais: uma análise a partir do roteiro Caminhos Rurais de Porto Alegre - RS e do Projeto Viva Ciranda, Joinville - SC', realizada no ano de $2011^{1}$.

Para tal, utilizou-se como procedimentos metodológicos a pesquisa bibliográfica, pesquisa documental, observação sistemática e entrevistas semiestruturadas, aplicadas a 22 professoras, responsáveis pelas turmas de alunos que visitaram as propriedades rurais pedagógicas nos meses de agosto a novembro de 2011. Deste grupo, 14 atuavam em escolas municipais de Joinville e 8, em escolas particulares de Porto Alegre.

Assim, além desta seção introdutória este artigo está estruturado em 5 seções. Na segunda seção expõem-se os desafíos da escola e dos processos de aprendizagem. $\mathrm{Na}$ terceira seção define-se o turismo rural pedagógico e suas interfaces, buscando evidenciar sua relação com a educação e os processos educativos. Na quarta seção apresentam-se os procedimentos metodológicos utilizados na pesquisa. Na quinta seção expõe-se uma síntese das atividades e objetivos de cada propriedade, dentro das duas experiências analisadas e em seguida, são analisadas as impressões dos professores em relação ao turismo rural pedagógico enquanto prática educativa. Finalmente, na última seção são apontadas as principais conclusões obtidas na pesquisa.

\footnotetext{
${ }^{1}$ Dissertação de mestrado apresentada como requisito para a obtenção do título de mestre em Desenvolvimento Rural no âmbito do Programa de Pós-Graduação em Desenvolvimento Rural (PGDR/UFRGS) em 2012.
} 


\section{OS DESAFÍOS DA ESCOLA DIANTE DAS CONFIGURAÇÕES DA SOCIEDADE CONTEMPORÂNEA}

Ao longo destes últimos anos, tem-se verificado uma série de mudanças tanto nas esferas social, política, econômica e cultural, quanto na ciência e tecnologia. Em meio a este cenário, o desenvolvimento e expansão das novas tecnologias de informação e comunicação (TICs) trouxeram à tona uma nova configuração social, ao introduzir novas formas de pensar e se relacionar com as pessoas e com o mundo. Por conseguinte, emerge uma geração que, cada vez mais precocemente, está dominando as TICs, as quais acabam influenciando no seu modo de estudar, aprender e compreender o mundo (SANTOS; SCARABOTTO; MATOS, 2011). São crianças e adolescentes que passam a maior parte de seu tempo conectadas aos jogos eletrônicos, celulares e redes sociais, vinculadas, por conseguinte, ao mundo virtual.

Mas, apesar deles deterem uma infinidade de informações essa nova geração, cada vez mais, tem evidenciado uma carência de vivências práticas, de experiências significativas relacionadas à natureza, que lhes permitam perceber um mundo que nem sempre é mostrado em sala de aula e tampouco na televisão ou na internet, despertando sensações e aprendizagens indeléveis essenciais ao processo de desenvolvimento.

Para Jolly et al. (2004), esse estilo de vida das crianças e jovens tem consequências preocupantes, acarretando uma série de problemas relacionados à saúde física e psicológica. Problemas como sobrepeso, transtornos alimentares, diabetes, sedentarismo e distúrbios de comportamento têm aumentado exigindo da sociedade novas estratégias que possibilitem um estilo de vida mais ativo e saudável.

Tais questões remetem a outra problemática, quais sejam os desafios e dilemas que o sistema educacional enfrenta diante desse novo perfil de estudante que frequenta as salas de aula. Desafios estes como, por exemplo, o desinteresse dos alunos, as relações conflituosas entre docentes e discentes, a indisciplina e a evasão escolar concorrem com as críticas relacionadas ao tipo de currículo, métodos avaliativos, conteúdos e metodologias adotadas nas escolas, bem como, ao (des) preparo dos professores frente às novas tecnologias de informação e comunicação.

Na análise de Duvoisin (2002) a escola deveria compreender que, no contexto o mais importante é que os alunos adquirissem uma aptidão geral para encarar os 
problemas e aprendessem princípios organizadores que possibilitassem relacionar os saberes e lhes conferir sentido. Trata-se de estimular a curiosidade, instigando sua aptidão interrogativa e orientando-os para os problemas fundamentais de sua época.

Barcelos (1999), por sua vez, expõe que a escola deveria, em primeira instância, possibilitar que as crianças crescessem integradas à sociedade e não submetidas a ela. Daí a necessidade e urgência em compreender o papel desempenhado pela escola diante das novas configurações da sociedade contemporânea e também, a importância de reavaliar as concepções sobre educação e suas implicações nos processos educativos propostos. Implica ainda, em reconhecer que a escola, embora exerça uma importante função social, não se constitui no único espaço que possibilita o desenvolvimento das potencialidades do indivíduo e de aquisição de conhecimentos.

Observa-se assim, uma ação pedagógica múltipla na sociedade, na qual o ato pedagógico vai muito além do âmbito escolar formal. Consequentemente, o educador já não é mais apenas o professor, mas também outras pessoas que atuam nos meios de comunicação, nos movimentos sociais, nos sindicatos, nas empresas e em tantas outras instâncias da sociedade. A educação formal, desse modo, não se limita exclusivamente à prática escolar, mas envolve outras instâncias, a exemplo da educação de adultos, educação sindical, profissional e assim por diante (LIBÂNEO, 2004).

Nessa conjuntura, segundo Gadotti (2000), a escola deveria servir de bússola, como elemento orientador que favorecesse uma formação geral voltada para a educação integral, superando dessa forma, a visão utilitarista cujo objetivo se restringe unicamente a oferecer informações "úteis" visando à competitividade, para a obtenção de resultados. Em face disso, "a escola precisa ter projeto, precisa de dados, precisa fazer sua própria inovação, planejar-se a médio e longo prazo, fazer sua própria reestruturação curricular, elaborar seus parâmetros curriculares, enfim, ser cidadã" (GADOTTI, 2000, p. 8).

Desta forma, verifica-se a necessidade de levar a cabo uma nova dinâmica, com novas metodologias e conteúdos que realmente tenham sentido para a vida do sujeito, desenvolvendo saberes que permitam aos educandos a apropriação de valores relacionados à sustentabilidade ambiental, à valorização da cultura, dos costumes, à responsabilidade social. 
Para tal, é imprescindível que os processos educativos não se limitem ao espaço da sala de aula ou até mesmo da escola, necessitando que sejam utilizados e reaproveitados outros contextos educativos. É o caso, por exemplo, da prática do turismo rural pedagógico, desenvolvido no âmbito das propriedades rurais, espaços estes que outrora eram vistos como locais sem qualquer função educativa e que têm emergido como verdadeiros laboratórios de aprendizagem ao ar livre.

\section{CONTRIBUIÇÕES DO TURISMO RURAL PEDAGÓGICO NO ÂMBITO DA EDUCAÇÃO}

Caracterizado por um conjunto de atividades educativas que utiliza como recurso didático as atividades agrícolas e pecuárias, bem como, os recursos naturais e culturais ali existentes, o turismo rural pedagógico emerge como uma alternativa inovadora que reflete as características do novo rural. Aspectos como educação, meio ambiente, agricultura familiar, universo rural e integração social representam alguns dos muitos elementos que envolvem esse tema atual.

Em face disso, o turismo rural pedagógico pode ser definido como uma atividade que perpassa por diferentes áreas do conhecimento. No âmbito da educação, o turismo rural pedagógico também tem ganhado visibilidade enquanto uma ferramenta de ensino que vai além da sala de aula, desenvolvida no âmbito das propriedades rurais em que os agentes educativos são os agricultores.

Dentro dessa perspectiva, o turismo rural pedagógico emerge como uma prática educativa que tem como elemento orientador a aprendizagem pela experiência. Segundo Yus (2002), a aprendizagem pela experiência compreende um processo que vincula a educação, o trabalho e o desenvolvimento pessoal; um processo que exige métodos ativos, rompendo assim com o esquema tradicional de alunos passivos e receptivos.

Nesse contexto, as propriedades rurais passam a receber um novo enfoque a partir do momento em que se abrem para receber crianças e adolescentes provenientes de escolas, com o propósito de mostrar o trabalho dos agricultores, bem como seus saberes e conhecimentos adquiridos ao longo dos tempos. 
$\mathrm{Na}$ análise de Caffarelli et al. (2010), as propriedades rurais representam ferramentas pedagógicas eficazes que favorecem o crescimento da consciência do papel social da agricultura e das áreas rurais e, numa perspectiva de desenvolvimento, contribuem para a valorização dos recursos históricos, arqueológicos e culturais de um determinado território.

Ohe (2012), a partir de pesquisas realizadas no Japão, evidencia que esta nova função desempenhada pela agricultura, qual seja, a função educativa, tem se difundido e atraído cada vez mais atenção, não só dos países desenvolvidos, mas também dos países em desenvolvimento. Tal fato está associado a questões relacionadas à perda de hábitos alimentares saudáveis tradicionais, e, por conseguinte, ao distanciamento cada vez maior entre vidas rurais e urbanas, apesar do rápido progresso no transporte e tecnologia da informação. De acordo com o autor, experiências envolvendo propriedades rurais pedagógicas proporcionam oportunidades de lazer e também a possibilidade de aprender o que não pode ser experimentado na vida urbana, tais como sobre a origem dos alimentos. Ao mesmo tempo, esta função educativa favorece um novo papel social aos agricultores e fonte de renda em face da estagnação dos preços dos produtos agrícolas.

Em face disso, Jolly et al. (2004, p. 633) argumentam que a utilização da propriedade rural como recurso pedagógico no cenário constitui-se em importante “[...] fonte de renda para o agricultor, como uma plataforma pedagógica para o ensino e como fonte de identidade para uma população que está cada vez mais distante da agricultura e da produção primária”.

Em relação propriamente às atividades educativas, Nasolini (2005) aponta três ideias básicas que orientam essa prática nas propriedades rurais. A primeira está relacionada a uma pedagogia ativa, do "aprender fazendo", representada por um conjunto diversificado de atividades práticas e experiências diretas; a segunda refere-se ao contato direto com animais e plantas em seu ambiente natural; e a terceira compreende a oportunidade de encontro e interação entre agricultores e jovens, possibilitando o enriquecimento das experiências destes últimos.

De acordo com Franco e Senni (2005), o caráter inovador que caracteriza esse tipo de formação educativa está justamente no desenvolvimento de uma nova metodologia de ensino conhecida como "ensinar fazendo", realizada por meio de diferentes atividades e recursos. 
Nesse sentido, segundo Gurrieri (2008), as propriedades rurais pedagógicas podem representar um momento de interação com o mundo da escola, favorecendo a participação ativa dos estudantes por meio de atividades que permitem "aprender fazendo" visando a promoção da educação ambiental e alimentar, não somente com as crianças e jovens, mas também com suas respectivas famílias.

Diante dessa conjuntura, D’Agostino (2008) expõe que um dos objetivos das atividades desenvolvidas na propriedade rural é proporcionar às crianças e aos jovens maneiras de viver em harmonia com o meio ambiente, por meio de situações concretas e não somente proporcionar um conhecimento proveniente do mundo virtual, obtido por meio da internet e da televisão.

Além de servir como ferramenta para a promoção da educação ambiental e nutricional, as propriedades rurais pedagógicas possuem outros objetivos, que na perspectiva de De Caffarelli et al. (2010) compreendem: a) propor diferentes abordagens pedagógicas que possibilitem aos envolvidos um ensino com base no real e no concreto; b) introduzir a economia agrícola, possibilitando aos jovens e adultos uma compreensão mais clara acerca dessa atividade; c) possibilitar a compreensão das relações entre cidade e campo e as ligações existentes entre as áreas econômicas, sociais, culturais e ambientais; d) contribuir para o desenvolvimento local, reforçando as parcerias entre os atores locais; e) capacitar os jovens.

Para além dessas questões, o turismo rural pedagógico desenvolvido nas propriedades rurais constitui uma importante ferramenta socio-educativa, que possibilita às gerações um verdadeiro 'mergulho' no mundo das experiências, das brincadeiras ao ar livre, das trocas sociais e culturais, possibilitando assim, uma infância marcada não pelo tempo cronológico e pelas instruções acabadas, mas pelas experiências vividas e pelos cheiros, sensações e sabores sentidos junto à terra, em contato com a natureza, os animais, as plantas.

\section{PROCEDIMENTOS METODOLÓGICOS}

Este artigo compreende um recorte do projeto de pesquisa realizado em nível de mestrado no Programa de Pós-Graduação em Desenvolvimento Rural (PGDR/UFRGS). 
O estudo, intitulado 'Turismo rural pedagógico e a função educativa das propriedades rurais: uma análise a partir do roteiro Caminhos Rurais de Porto Alegre, RS e do Projeto Viva Ciranda, Joinville, SC', teve como principal objetivo analisar as atividades que caracterizavam o turismo rural pedagógico, tendo como enfoque a sua adequação enquanto prática educativa a ser desenvolvida em complemento ao ensino escolar.

No referido estudo, utilizou-se como procedimentos metodológicos a pesquisa bibliográfica, pesquisa documental e observação sistemática das atividades educativas realizadas nas propriedades rurais participantes do Projeto Viva Ciranda, em Joinville SC e do Projeto Caminhos Rurais de Porto Alegre, RS. Complementarmente, foram realizadas entrevistas semiestruturadas, as quais foram aplicadas junto a dois grupos distintos: o primeiro, constituído por proprietários rurais, donos das propriedades rurais que desenvolvem atividades de turismo rural pedagógico; e o segundo, composto por 22 professoras responsáveis pelas turmas que visitaram as propriedades no ano de 2011.

Tal recorte, desse modo, concentra-se nas entrevistas realizadas com esse grupo de professoras, buscando a partir dos resultados obtidos, discutir a respeito da impressão dessas profissionais sobre o turismo rural pedagógico enquanto prática educativa que favorece a aprendizagem dos alunos. No total, foram entrevistadas 22 professoras, sendo 14 de Joinville e 8 de Porto Alegre. Todas as entrevistadas acompanharam suas turmas em visitas às propriedades rurais pedagógicas analisadas entre os meses de agosto a novembro de 2011.

Em relação à formação das entrevistadas, as professoras do município de Joinville eram formadas em Pedagogia, sendo que a maioria também possuía pósgraduação. Já, as professoras entrevistadas durante a pesquisa de campo realizada no Roteiro "Caminhos Rurais", a formação inicial evidenciou um quadro diverso de profissionais, contemplando desde professoras com formação em Geografia, Ciências Biológicas até Letras e Pedagogia. Das seis entrevistadas, cinco delas atuavam em turmas dos anos finais do ensino fundamental $\left(6^{\circ}\right.$ ao $9^{\circ}$ ano). Apenas uma das professoras entrevistadas lecionava para turmas dos $2^{\circ}$ e $3^{\circ}$ anos do ensino fundamental.

Quanto às experiências analisadas, ressalta-se que o roteiro "Caminhos Rurais" de Porto Alegre estava compreendendo uma proposta de turismo rural desenvolvida nas áreas rurais da zona sul do município de Porto Alegre, capital do Estado do Rio Grande do Sul. Nesse roteiro, encontravam-se as propriedades que estavam desenvolvendo 
atividades de caráter educativo, voltadas especificamente para grupos de estudantes do ensino fundamental dos anos iniciais $\left(1^{\circ}\right.$ ao $5^{\circ}$ ano) e também, dos anos finais $\left(6^{\circ}\right.$ ao $9^{\circ}$ ano). As escolas que visitaram estas propriedades eram todas privadas, localizadas na área urbana do município de Porto Alegre.

Dentre as propriedades visitadas estavam: Sítio do Tio Juca, Sítio dos Herdeiros, Sítio do Mato, Sítio Recanto das Pedras e Granja Santantonio. São pequenas propriedades com área física total variando entre 1 e 11 hectares, cuja atividade principal estava concentrada na produção agroecológica.

A outra experiência analisada foi o Projeto "Viva Ciranda" e compreendia uma proposta de turismo pedagógico que estava sendo desenvolvida no município de Joinville, localizado na região nordeste do Estado de Santa Catarina. Faziam parte do projeto seis propriedades rurais: Agrícola da Ilha, Propriedade da Família Schroeder, Sítio Vale das Nascentes, Apiário PFAU, CTG Chaparral e Propriedade do Senhor Ango Kersten. Em relação ao tamanho, as propriedades pesquisadas variaram entre 9 e 500 hectares, com a grande maioria possuindo entre 9 e 53 hectares. Ressalva-se que as escolas que realizaram as visitações eram públicas. As turmas, por sua vez, eram geralmente dos anos iniciais $\left(1^{\circ}\right.$ ao $5^{\circ}$ ano $)$ do ensino fundamental.

\section{RESULTADOS E DISCUSSÕES}

Embora a proposta desse artigo tenha como objetivo principal apresentar a percepção das professoras entrevistadas em relação à prática do turismo rural pedagógico considera-se relevante expor o contexto das duas experiências pesquisadas: o projeto "Viva Ciranda" (Joinville, SC) e o Roteiro "Caminhos Rurais" (Porto Alegre, RS). Conhecer os roteiros desenvolvidos nessas propriedades, mesmo que sucintamente, permite compreender os aspectos relevantes de tal proposta no que diz respeito à aprendizagem das crianças. 


\subsection{ROTEIRO “CAMINHOS RURAIS” DE PORTO ALEGRE}

Embora fosse uma proposta em processo de desenvolvimento desde o final da década de 1990, somente no ano de 2005, o roteiro foi inaugurado oficialmente (RODRIGUES, 2011).

$\mathrm{Na}$ época, a Secretaria Municipal do Turismo de Porto Alegre, em parceria com a Associação Rio-grandense de Empreendimentos de Assistência Técnica e Extensão Rural (EMATER) e o Serviço Nacional de Aprendizagem Rural (SENAR) passaram a auxiliar os agricultores familiares indicando os melhores locais de suas propriedades que poderiam ser mostrados aos turistas, em virtude da importância cultural ou beleza natural existente. A partir da identificação dessas propriedades interessadas na realização da atividade do turismo rural, foi criado, então, o roteiro turístico "Caminhos Rurais” de Porto Alegre (SOUZA; ELESBÃO, 2009).

Segundo Rodrigues (2011), o roteiro "Caminhos Rurais" estava contemplando no ano de 2011 o equivalente a 31 empreendimentos, distribuídos em onze bairros localizados na zona sul de Porto Alegre, oferecendo desde opções de lazer, gastronomia e hospedagem até experiências relacionadas à rotina de vida rural. Este roteiro não foi planejado para desenvolver exclusivamente atividades pedagógicas. No entanto, algumas propriedades começaram a receber grupos de alunos $\mathrm{e}$ as atividades começaram a criar um caráter mais educativo.

Desse grupo, cinco ganharam notoriedade e passaram a ser caracterizadas como propriedades rurais que praticavam o turismo rural pedagógico. Em relação a essas propriedades rurais pedagógicas, o estudo permitiu identificar o conjunto de atividades propostas, bem como, o objetivo principal dos roteiros desenvolvidos:

- Sítio do Tio Juca: visitação às áreas de cultivo (hortaliças e plantas frutíferas) e roda de discussões. O objetivo principal era mostrar às crianças a forma de produção agroecológica e o trabalho do produtor rural.

- Sítio dos Herdeiros: visitação ao pomar de ameixas, à horta e aos espaços onde estavam os pequenos animais (coelhos, ovelhas, patos). O principal objetivo era mostrar o trabalho do agricultor no seu dia a dia, como era feito o plantio e colheita das frutas e hortaliças e os cuidados necessários para o desenvolvimento das mesmas. 
- Sítio do Mato: trilha ecológica em meio à mata nativa, visitação ao estábulo, ao curral e aos canteiros da pequena horta feita com pneus, jogos recreativos. O objetivo principal era oportunizar às crianças em idade escolar vivências no meio rural.

- Sítio Recanto das Pedras: visitação aos espaços onde estavam os animais (ovelha, cavalo, coelhos, patos) e à horta pedagógica (relógio humano, espiral de ervas medicinais e mandala), oficina de alimentação saudável, onde as crianças participavam da fabricação de pães. O objetivo era incentivar as crianças para que tivessem uma alimentação mais saudável e, ao mesmo tempo, promover o resgate da cultura rural.

- Granja Santantonio: visitação nas áreas de cultivo de hortaliças, onde as crianças tinham a oportunidade de participar do plantio e colheita; passeio de trator e contato com os animais da propriedade (cavalo, gansos, patos). O roteiro tinha como objetivo mostrar todos os aspectos que caracterizavam o modo de produção agroecológica e, concomitantemente, possibilitar às crianças que conhecessem o trabalho do agricultor, seus costumes e tradições.

\subsection{PROJETO "VIVA CIRANDA"2}

Oficialmente inaugurado em março de 2011, o projeto começou a ser idealizado ainda em 2010 por uma equipe de profissionais da Fundação Turística de Joinville (PROMOTUR) que, percebendo o cenário favorável existente na região, não somente em relação aos atrativos naturais e culturais, mas, sobretudo, pelo público potencial presente, relacionado ao número de estudantes, decidiu investir e elaborar uma proposta envolvendo propriedades rurais e escolas.

Assim, no ano de 2010, o projeto foi estruturado em várias etapas, a começar pela seleção das propriedades que apresentavam potenciais ou que já tinham alguma experiência de turismo rural pedagógico; a realização do diagnóstico das propriedades, objetivando conhecer as características físicas e estruturais das mesmas e o perfil dos proprietários; a contratação de uma pedagoga para assessorar os proprietários. Para isso, a profissional visitou as propriedades, conversou com os agricultores e, a partir dos

\footnotetext{
${ }^{2}$ Todas as informaç̃̃es relacionadas especificamente ao histórico do projeto 'Viva Ciranda' foram obtidas por meio conversas informais junto ao coordenador do projeto, Vinicius Boneli Vieira no ano de 2011, à assessora técnica, Thaise Costa Guzzatti e à pedagoga do Projeto, Anelise Falk, durante os primeiros contatos com as propriedades rurais participantes do projeto, no primeiro semestre de 2011.
} 
recursos identificados em cada uma delas, preparou entre duas e três atividades para serem desenvolvidas nesses locais. A partir daí estabeleceu-se uma parceria com a Secretaria da Educação Municipal, que disponibilizou um ônibus e selecionou uma escola para a realização do teste-piloto no segundo semestre de 2010.

Com esse teste, foram gerados fotos e materiais para a elaboração de uma cartilha, visando à elaboração de uma proposta maior, a qual foi apresentada ao Ministério do Turismo em dezembro de 2010, e cuja aprovação ocorreu no mesmo mês. O referido órgão governamental disponibilizou recursos financeiros para a execução do projeto, o que permitiu subsidiar 55 visitas de turmas de alunos de quatro escolas municipais de Joinville às propriedades, bem como a confecção do material de divulgação e treinamentos.

No que diz respeito às seis propriedades pesquisadas, o estudo possibilitou conhecer um conjunto diversificado de atividades educativas propostas em cada propriedade, que contemplavam diferentes atividades produtivas, abrangendo desde a produção de melado, o cultivo de flores, frutas, tubérculos e hortaliças de forma orgânica até atividades de educação ambiental e de criação de animais de pequeno porte, quais sejam:

- Agrícola da Ilha: visitação ao jardim dos Hemerocallis e ao jardim dos sentidos (pedra sussurrante, labirinto dos sons, pedra das cores, pedra d'água) e também, trilha pela mata nativa até o lago dos peixes ornamentais. O propósito era mostrar às crianças a importância das plantas para a vida delas, para o meio ambiente, além, das explicações em relação ao processo de produção e cultivo de flores hemerocallis.

- Propriedade da Família Schroeder: visitação à horta orgânica, ao pomar e jardim, bem como, atividades de interação com pequenos animais como segurar os coelhos, patinhos; alimentar o porco, o cabritinho; tirar leite da cabra. Tal roteiro visava, sobretudo, apresentar o dia a dia dos agricultores, mostrando as atividades agrícolas e pecuárias desenvolvidas na propriedade, por meio de experiências diferenciadas em contato direto com a terra, os animais e as plantas.

- Sítio Vale das Nascentes: voltada para a produção de frutas (pomar com de frutas exóticas) e cultivo de hortaliças (para consumo interno), as atividades desenvolvidas nessa propriedade tinham como principal objetivo promover a educação ambiental, especialmente com relação aos recursos hídricos. 
- Apiário PFAU: a apresentação do mundo das abelhas, atividades lúdicas de identificação das colmeias e das abelhas, caminhada ecológica até o Rio da Prata. O propósito era mostrar às crianças o mundo das abelhas, destacando o importante papel desempenhado por esses insetos no equilíbrio da natureza.

- CTG Chaparral: a propriedade tinha como ênfase a criação de cavalos crioulos e abrangia desde a apresentação de suas características, hábitos e comportamentos, bem como, atividade de laço e montaria e passeio de charrete pela propriedade. O objetivo era promover uma compreensão mais aprofundada acerca da criação e doma dos cavalos.

- Propriedade do Senhor Ango Kersten: Passeio de trator pela propriedade, observação do sistema de tratamento de água feito com raízes de junco, além da visitação ao museu rural e ao curral onde estavam os pequenos animais e aves que viviam na propriedade. Tal roteiro tinha como principal propósito vivenciar diferentes experiências em contato com a produção agrícola, o meio ambiente e a cultura do mundo rural.

\subsection{IMPRESSÕES DAS PROFESSORAS SOBRE AS ATIVIDADES EDUCATIVAS DESENVOLVIDAS}

A impressão das professoras entrevistadas em relação às atividades propostas nas propriedades das duas experiências analisadas foi, em geral, bastante positiva. Para todas elas, as atividades, pelas características que apresentaram, poderiam ser consideradas como práticas educativas. A maioria das professoras que visitaram as propriedades, tanto no município de Joinville quanto em Porto Alegre, avaliou como interessantes sob o ponto de vista de prática educativa os roteiros desenvolvidos, com atividades e explicações relevantes que iam ao encontro das questões trabalhadas em sala de aula, aspecto muito importante no processo de ensino e aprendizagem. Outro elemento destacado referiu-se à relação com o ambiente e o meio rural, possibilitado por estas atividades. Estes resultados podem ser verificados nos depoimentos coletados juntos às entrevistadas e que são apresentados na sequência:

Penso que podem sim ser consideradas práticas educativas, porque trabalha essa parte de sustentabilidade, usa os recursos naturais de forma sustentável, 
equilibrada mostrando que a gente pode sim conviver de maneira harmoniosa com o ambiente e ter uma produção que não agrida o solo, a natureza. Outra coisa que mostra é que viver da agricultura é possível, que você vivendo da agricultura vai ter uma renda como nas demais profissões (professora responsável pela turma do $7^{\circ}$ ano, em visita ao Sítio do Tio Juca, do Roteiro Caminhos Rurais de Porto Alegre).

Eu acho que é super válido, pois os alunos vêm de uma realidade completamente diferente e são poucos os que têm o contato direto com o meio ambiente, de conhecer os animais [...] eles podem não usar aquele conhecimento das aves, por exemplo, nesse ano, mas no ano que vem eles vão estudar, então vão lembrar-se do que viram aqui, a vivência sempre é importante (professora responsável pela turma de alunos do $5^{\circ}$ ano, em visita ao Sítio do Mato, do Roteiro Caminhos Rurais de Porto Alegre).

Sem dúvida, podem sim ser consideradas como práticas educativas, pois estão bem dentro do que eu trabalhei com eles na sala de aula, com os conteúdos, desde a parte do lixo, até a parte ali das nascentes (professora da turma do $4^{\circ}$ ano, em visita à propriedade Vale das Nascentes, do Projeto Viva Ciranda).

A valorização de tais atividades pelas profissionais entrevistadas revela a importância de experiências como estas para as crianças em idade escolar. Os roteiros das duas experiências analisadas possibilitaram não apenas a compreensão de conteúdos trabalhados nas disciplinas em sala de aula, mas principalmente, vivências práticas que permitiriam a estas crianças um contato direto com o rural, a natureza, estando de acordo com o que foi afirmado por Nasolini (2005).

Tal averiguação pôde ser constatada claramente no questionamento acerca da importância desse tipo de atividade para as crianças, ou seja, o que elas aprendiam nessas propriedades. $\mathrm{Na}$ análise das professoras, as atividades desenvolvidas nas propriedades rurais emergiram como importante ferramenta permitindo aos alunos vivenciar na prática o que era ensinado em sala de aula, favorecendo experiências múltiplas que nem sempre eram possíveis em seu cotidiano.

Eu acho que o que eles viveram lá, junto com o que nós trabalhamos aqui, é um tipo de atividade que eles nunca vão esquecer, e a gente percebe isso até pelo depoimento dos pais. Eles em casa querem ajudar os pais na horta, os que não têm, convenceram os pais a fazer, as mudinhas de alface que sobraram também quiseram levar para casa, para plantar, cuidar [...] (professora responsável pela turma do $3^{\circ}$ ano, em visita à propriedade da Família Schroeder, do projeto "Viva Ciranda").

O contato direto com a natureza é muito importante e eles não têm tanto contato com esse tipo de ambiente. A questão da autoestima, o conhecimento dos conteúdos explorados lá, a possibilidade de conhecer diversas qualidades 
de plantas, de palmeiras; e a parte dos sentidos, de poder passar por essa experiência de estar tocando, sentido, eu acho de fundamental importância para o aprendizado deles (professora responsável por turma do $3^{\circ}$ ano, em visita à propriedade Agrícola da Ilha, do projeto Viva Ciranda).

Tem muita criança que não tem essa vivência, a maioria das nossas crianças são crianças de cidade, criadas em apartamento e elas não têm esse contato com os animais, com a terra, com plantas, com a natureza [...] Eles não conhecem quase nada hoje em dia, sobre a origem dos alimentos, sobre essas vivências e aqui é uma oportunidade de ter tudo isso (professora da turma do $2^{\circ}$ ano, em visita à propriedade Recanto das Pedras, do Roteiro Caminhos Rurais de Porto Alegre).

É um tipo de atividade que possibilita o contato com a terra, com as plantas, uma experiência única para muitas crianças, ainda mais que a maioria delas vive em apartamentos, meio isolados, sem a chance de vivenciar essas coisas. $\mathrm{O}$ que elas podem aprender aqui? Várias questões relacionadas ao plantio, ao manejo, ao modo de produção agroecológico, ao que é orgânico, ao meio rural em si, comparando com a cidade, com o lugar onde moram (professora do $6^{\circ}$ ano, em visita com a turma à Granja Santantonio, do Roteiro Caminhos Rurais de Porto Alegre).

De acordo com a grande maioria das professoras, as atividades, além de favorecer o aprendizado dos alunos em relação aos conteúdos específicos desenvolvidos em sala de aula, também possibilitavam a compreensão e valorização do trabalho do agricultor e das suas atividades produtivas, confirmando a afirmação de Caffarelli et al. (2010) sobre a importância de ressaltar o papel social da agricultura para as crianças. Quando questionadas sobre as contribuições das atividades agrícolas e da produção agropecuária para o aprendizado das crianças, observou-se uma convergência em relação à percepção acerca dessa questão.

Todas as professoras destacaram que o contato com esse tipo de atividade enriqueceria o universo cultural das crianças, além de favorecer a compreensão acerca da origem dos alimentos, do patrimônio rural e o incentivo a conscientização ambiental, o que se encontrou em consonância com as afirmações de Ohe (2012) e Gurrieri (2008) no que tange à educação alimentar e ambiental. Esse contato, que a maioria dos estudantes nunca vivenciou anteriormente, sobretudo, por viverem em centros urbanos, favoreceu conhecimento, mas também, experiências que muitos jamais esqueceriam, pelo grau de significância atribuído. São experiências que permitiram outra visão do rural, do agricultor, da natureza, que despertam os sentimentos, as sensações, a imaginação e a criatividade, conforme foi destacado anteriormente por Nasolini (2005).

Outro aspecto analisado refere-se à avaliação das professoras sobre a interação dos proprietários rurais com os alunos durante o desenvolvimento das atividades 
educativas. A receptividade, a linguagem utilizada e a abordagem adotada estão entre as questões avaliadas. No grupo de professoras que visitaram as propriedades do Projeto "Viva Ciranda", percebeu-se que houve certa surpresa em relação à maneira como os proprietários interagiram com as crianças e desenvolveram as atividades, sobretudo, pela didática evidenciada. O preparo dos proprietários e a forma como se dirigiam às crianças, bem como, a maneira como comunicaram as informações são aspectos que foram destacados por praticamente todas as professoras entrevistadas.

Emergiu daí um consenso geral a respeito do perfil dos proprietários, qual seja, embora não tendo uma formação na área da educação, podiam sim trabalhar com o público escolar, pois demonstraram possuir uma linguagem simples e adequada, interagindo com facilidade com as crianças. Foram pessoas atenciosas e que expressaram um sentimento muito positivo pelo trabalho que faziam.

Por outro lado, na visão do grupo de professoras que visitaram as propriedades do Roteiro "Caminhos Rurais" observou-se que, embora houvesse vários pontos convergentes com as percepções das professoras de Joinville, algumas professoras evidenciaram que os proprietários poderiam explorar mais o que sabiam, pois mostraram receio em demonstrar seus saberes. Nesse sentido, a sugestão proposta pelas entrevistadas, associou-se à realização de um trabalho mais direto com esses proprietários, no sentido de esclarecer que os conhecimentos e as atividades que desenvolviam em suas propriedades tinha importância no contexto e de grande valia, em termos pedagógicos. Este importante aspecto foi evidenciado claramente através dos depoimentos das professoras entrevistadas na pesquisa e que são apresentados na sequência deste artigo:

É perfeito, eles sabem como tratar as crianças, não usam uma linguagem muito difícil, sabem como falar, como explicar, muito bom (professora de turma do $4^{\circ}$ ano, em visita à propriedade do Senhor Ango Kersten, do projeto Viva Ciranda).

Achei muito legal, parecia até que eles (os alunos) já conheciam o Dodô, uma pessoa simples e atenciosa, o próprio apelido é uma atração para as crianças. E ele, pela simpatia dele, pelo carisma dele, jeito de conversar com as crianças, de brincar, de correr naquele espaço com eles, isso foi muito bom, prazeroso, [...] (professora da turma do $4^{\circ}$ ano, em visita ao Sítio dos Herdeiros, do Roteiro Caminhos Rurais de Porto Alegre). 
As impressões das professoras, portanto, estiveram em consonância não apenas ao que foi constatado nas observações realizadas, mas também, nas análises teóricas dos autores referendados neste texto. Verificou-se desse modo, que a prática do turismo rural pedagógico emergiu como uma importante ferramenta capaz de facilitar a aprendizagem dos conteúdos desenvolvidos em sala de aula.

Concomitantemente oportunizaria para a geração de crianças e adolescentes um conjunto de experiências incomuns nas suas vidas cotidianas, permitindo a esta geração, um contato mais próximo com a natureza, com o rural e com o patrimônio cultural, aspectos que, parecem estar cada vez mais distantes da vida desses jovens.

\section{CONSIDERAÇÕES FINAIS}

O turismo rural pedagógico compreende uma atividade de significativo valor para a educação no cenário em que as pessoas se encontram. $\mathrm{O}$ fato de envolver atividades que são desenvolvidas no ambiente rural e natural, de utilizar os saberes e fazeres tipicamente rurais e de possibilitar o contato direto com animais e plantas torna esse tipo de prática um importante instrumento educativo que estimula desde a educação ambiental, o resgate e valorização da cultura rural até a educação alimentar e nutricional ressaltada nas discussões acerca da origem dos alimentos, dos benefícios de uma alimentação saudável, do valor nutricional de certos alimentos e das propriedades medicinais de algumas plantas.

Tais aspectos afluíram com as impressões destacadas nos depoimentos das 22 professoras entrevistadas e evidenciaram a necessidade desse tipo de atividade ser utilizado com mais frequência pelas escolas, em complemento ao ensino de sala de aula, proporcionando experiências diferenciadas aos alunos. Contudo, para que isso aconteça seria preciso inicialmente que as escolas conhecessem esses espaços, soubessem o que é o turismo rural pedagógico e quais as suas contribuições para o aprendizado dos alunos. E também que percebessem que os proprietários rurais poderiam ser importantes parceiros nesse processo.

Muitas professoras passaram a ter uma visão mais concreta desse tipo de atividade, considerando-as como práticas educativas, somente depois de conhecer in 
loco o trabalho e as atividades desenvolvidas pelos agricultores. Do mesmo modo, a valorização dos saberes e fazeres dos agricultores/proprietários rurais também só passou a ser reconhecida por eles mesmos após vivenciarem tal experiência.

Verifica-se, pois, uma maior valorização por parte das professoras entrevistadas em relação às experiências proporcionadas nestes espaços e o quanto as atividades práticas são significativas para o aprendizado das crianças. Os depoimentos também revelaram a preocupação destas profissionais quanto ao modo de vida das crianças e adolescentes neste início do século XXI, cujas vivências são poucas e o contato direto com a natureza torna-se cada vez mais distante.

Tais impressões corroboraram com as concepções dos estudiosos acerca da necessidade urgente de possibilitar aos estudantes experiências diversas que favoreçam a ampliação do seu universo cultural, não se limitando unicamente ao espaço da sala de aula, indo para além dos muros escolares. Neste sentido, a escola poderia criar estratégias que atraíssem as crianças ao mundo do conhecimento e o turismo rural pedagógico emergiria como uma ferramenta ideal para este contexto.

A reflexão final converge para uma conclusão, qual seja a de que a prática do turismo rural pedagógico permite aos alunos experiências enriquecedoras e indeléveis; aos professores, uma maneira eficaz de ensinar os conteúdos trabalhados em sala de aula; à escola, uma forma eficiente de relacionar teoria e prática e ao mesmo tempo, de promover o resgate do patrimônio cultural; e à sociedade em geral, um modo de perceber a relação existente entre a função educativa desempenhada pela agricultura e pelos espaços rurais e a sua ligação com as funções social, ambiental, cultural e de saúde e segurança alimentar.

\section{REFERÊNCIAS}

BARCELOS, V. Educação Ambiental, infância e imaginação. In: QUAESTIO. Revista de Estudos da Educação. v. 1, n. 1. Sorocaba, SP: Unesp, 1999.

CAFFARELLI, J.; COQUILLAUD, M.-S.; DANIEL, V.; THOU, M. Creér une ferme pédagogique: de l'idée à la realization. França: Educagri Editions, 2010.

D’AGOSTINO, L. Il profilo e le caratteristiche di una Fattoria Didattica. In: La rete delle Aziende e delle Fattorie Didattiche in Sicilia. La documentazione 
dell'esperienza. V. 2. Regione Sicilia/Arpa, 2008. Disponível em: <www.arpa.sicilia.it/UploadDocs/1369_Fattorie_Didattiche.pdf $>$. Acesso em: $12 / 07 / 2011$.

DUVOISIN, I. A. A Necessidade de uma visão sistêmica para a educação ambiental: conflitos entre o velho e os novos paradigmas. In: RUSCHEINSKY, A. (Org.). Educação Ambiental: abordagens múltiplas. 1 ed. Porto Alegre: ArtMed, 2002, v. 1, p. 91-104.

FRANCO S.; SENNI, S. La funzione sociale dell'agricoltura. Il caso del Lazio, Quaderno ISE, n. 15, Regione Lazio - Università della Tuscia, 2005. Disponível em: <www.grupponoise.it/files/doc02.pdf>. Acesso em: 15/07/2011.

GADOTTI, M. Perspectivas atuais da educação. Porto Alegre: Editora. Artes Médicas, 2000.

GURRIERI, C. Scuola in Fattoria: dal produttore al consumatore verso un consumo consapevole. In: La rete delle Aziende e delle Fattorie Didattiche in Sicilia. La documentazione dell'esperienza. V. 2. Regione Sicilia/Arpa, 2008. Disponível em: <http://www.arpa.sicilia.it/wp-content/uploads/2014/06/Fattorie_Didattiche.pdf.>.

Acesso em: 20/07/2011.

JOLLY, L.; KROGH, E.; NERGAARD, T.; PAROW, K.; VERSTAD, B. The Farm as a Pedagogical Resource: background for and evaluation of the co-operation between agriculture and primary school in the county of Nord-Trondelag, Norway. In: SIXTH EUROPEAN IFSA SYMPOSIUM, 2004, Portugal. Proceedings of the Sixth European IFSA Symposium: Farming and Rural Systems - Research and Extension. Vila Real, Portugal: UTAD, 2004. p. 497-507. Disponível em: <www.livinglearning.org/.../The_Farm_as_a_Pedagogical_ResourcePortugal.pdf >. Acesso em: 05/03/2011.

KLEIN, A.; TROIAN, A.; SOUZA, M. O turismo rural pedagógico e a educação ambiental: as ações pedagógicas desenvolvidas na fazenda quinta da estância grande Viamão (RS). Revista Eletrônica do Mestrado em Educação Ambiental, v. 27, p. 107-121, 2011. Disponível em: 〈http://www.remea.furg.br/edicoes/vol27/art8v27.pdf〉. Acesso em: 20/01/2012.

LIBÂNEO, J. C. Pedagogia e pedagogos, para quê? 7. ed. São Paulo: Cortez, 2004.

MAGAlHÃES, H. G. D. A pedagogia do êxito: projetos de resultado. Petrópolis, RJ: Vozes, 2004.

NASOLINI, T. Educare all'ambiente e all'alimentazione. In: BERTOLINI, S. (Ed.). Nuovi educatori ambientali: Esperienze seminariali nel Master in Educazione Ambientale. V. 4, Bologna: Regione Emilia-Romagna, 2005. p. 233- 239.

Disponível em:

$<$ http://www.ermesambiente.it/wcm/infea/sezioni_laterali/formazione/master_in_ea/Ma ster_EA/master_ea/infean4.pdf >. Acesso em: 20/06/2011. 
OHE, Y. Operators' attitudes on educational tourism in agriculture. In: PINEDA, F. D.; BREBIA, C. A. (Orgs). Sustainable Tourism V (Fifth International Conference on Sustainable Tourism). UK, Southampton: WIT Press, 2012. p. 273-286.

RODRIGUES, M. C. Pedagogias do turismo rural e patrimonialização da natureza: uma análise estrutural dos Caminhos Rurais de Porto Alegre. 2011. Dissertação (Mestrado em Educação) - Programa de Pós-Graduação em Educação, Universidade Luterana do Brasil, Canoas, RS. 2011.

SANTOS, M.; SCAROBOTTO, S. do C.; DOS ANJOS; MATOS, E. L. M. Imigrantes e Nativos Digitais: um Dilema ou Desafio na Educação? In: X CONGRESSO NACIONAL DE EDUCAÇÃO - EDUCERE. I SEMINÁRIO INTERNACIONAL DE REPRESENTAÇÕES SOCIAIS, SUBJETIVIDADE E EDUCAÇÃO. 2011, Curitiba. p. 15.840-15.851. Disponível em:

<http://educere.bruc.com.br/CD2011/pdf/5409_3781.pdf;>. Acesso em: 25/07/2013.

SOUZA, M. de, ELESBÃO, I. A Introdução de uma inovação Social entre Agricultores Familiares: o Turismo Rural em dois Roteiros do Estado do Rio Grande do Sul, Brasil. In: MORENO, L.; SÁNCHEZ, M. M.; SIMÕES, O. (Org.). Cultura, Inovação e Território. Lisboa-Coimbra: SPER, AEEA, ESAC-IPC. 2009.

TEIXEIRA, A. R.; WANDSCHEER, E. A. R.; Souza, M. A Multifuncionalidade da agricultura e a contribuição pedagógica do turismo rural. Extensão Rural (Santa Maria), v. 12, p. 129-140, 2005.

YUS, R. Educação integral: uma educação holística para o século XXI. Porto Alegre: Artmed. 2002.

Recebido em: 24-04-2015.

Aprovado em: 24-05-2015. 